\title{
Aplikasi Sensor Acousto-Ultrasound Dan Atmega328 Untuk Alat Uji Tak Rusak Pada Peluruhan Kayu Bagian Dalam
}

\author{
Aan Darmawan ${ }^{1}$, Raymond Hianjaya ${ }^{1}$
}

\begin{abstract}
Inner-wood decay is hard to be detected. This research focused on inner-wood decay detection for Mahogany and Albasia Wood. Inner-wood decay can increase the possibility for tree or wood structure to collapse. An instrument is needed to detect inner-wood decay. Nondestructive testing (NDT) is one of the analyze technique for evaluating characteristic of a material. In this research, NDT is use as the analyze technique for getting the wood condition. There is lots of method for NDT, in this research ultrasound method with through transmission technique is chosen. Through transmission technique observe the amount of ultrasound that is sent from transducer transmitter through the wood that is tested and received by the transducer receiver. The amount of ultrasound that received will be higher if there is no inner-wood decay in the tested wood. The instrument that has been designed and realized can detect and classified inner-wood decay. The percentage of success in detecting condition Mahogany Wood with good quality is $98 \%$, poor quality is $80 \%$, and mediocre quality is $74 \%$. The percentage of success in detecting condition Albasia Wood with good quality is $94 \%$, poor quality is $86 \%$, and mediocre quality is $72 \%$.
\end{abstract}

KEYWORDS: inner-wood decay, non-destructive testing, ultrasound, through transmission.

\begin{abstract}
ABSTRAK: Peluruhan kayu bagian dalam sulit untuk dideteksi. Penelitian ini terfokuskan pada pendeteksian peluruhan kayu bagian dalam pada Kayu Mahoni dan Kayu Albasia. Peluruhan kayu bagian dalam dapat meningkatkan kemungkinan suatu pohon atau struktur kayu untuk rubuh, oleh sebab itu diperlukan suatu alat untuk mendeteksi peluruhan kayu bagian dalam. Uji tak rusak (UTR) merupakan salah satu teknik analisa untuk mengevaluasi ciri dari suatu material. Pada penelitian ini, UTR digunakan sebagai teknik analisa untuk mendapatkan kondisi kayu. Terdapat banyak metode dalam UTR, pada penelitian iini digunakan metode ultrasound dengan teknik through transmission. Teknik through transmission memperhatikan jumlah ultrasound yang terkirim dari transduser pemancar melewati kayu yang diuji lalu diterima transduser penerima. Jumlah ultrasound yang diterima transduser penerima akan lebih banyak apabila kayu tidak mengalami peluruhan kayu bagian dalam. Alat yang telah dirancang dan direalisasikan berhasil mendeteksi dan mengklasifikasi peluruhan kayu bagian dalam. Persentase keberhasilan mendeteksi kondisi kayu pada Kayu Mahoni dengan tanpa cacat adalah 98\%, dengan cacat $80 \%$, dan dengan cacat diisi sepihan kayu kering $74 \%$. Presentase keberhasilan mendeteksi kondisi kayu pada Kayu Albasia dengan tanpa cacat adalah 94\%. tanpa cacat adalah 86\%, dan cacat diisi serpihan kayu kering adalah $72 \%$.
\end{abstract}

KATA KUNCI: peluruhan kayu bagian dalam, uji tak rusak, ultrasound, through transmission.

\section{PENDAHULUAN}

$\mathrm{P}^{\mathrm{s}}$ eluruhan kayu bagian dalam umum terjadi pada suatu pohon atau struktur kayu akibat hewan, tumbuhan, cuaca maupun manusia. Peluruhan kayu bagian dalam ini dapat meningkatkan kemungkinan untuk rubuhnya suatu pohon atau struktur kayu [1]. Namun tidak mudah untuk mendeteksi peluruhan kayu bagian dalam, diperlukan suatu alat khusus untuk mendeteksinya [2]. Uji tak usak merupakan salah satu teknik analisis mengevaluasi ciri dari suatu material, komponen atau sistem tanpa merusak [3]. Terdapat enam metoda UTR yang paling sering digunakan, yaitu : ultrasound, arus eddy, partikel magnetik, penetran cair, radiografi, dan tes visual [4]. Pada penelitian ini metoda yang digunakan adalah ultrasound. Ultrasound dipilih karena tidak menyebabkan radiasi pengion (ionizing radiation) [5]. Pada penelitian ini dibuat alat UTR dengan ultrasound untuk mendeteksi peluruhan kayu bagian dalam pada Kayu Mahoni dan Kayu Albasia.

\section{METODOLOGI PENELITIAN}

Alat uji tak rusak dengan metoda ultrasound menggunakan dua transduser piezoelektrik yaitu pemancar dan penerima sebagai sensor ultrasonik dengan teknik inspeksi through transmission. Data yang didapat dari sensor ultrasonik akan dikirimkan ke mikrokontroler ATmega328 untuk mengklasifikasikan peluruhan kayu bagian dalam yang terjadi pada Kayu Mahoni dan Kayu Albasia.

\section{A. Uji Tak Rusak}

Uji tak rusak (UTR) atau biasa disebut Non-Destructive Testing (NDT) adalah teknik analisis yang umum dipakai pada teknologi sains dan industri untuk mendapatkan evaluasi ciri dari suatu material, komponen atau sistem. Teknik analisis ini tidak merusak atau mengubah permanen material, komponen atau sistem yang diuji.

\section{B. Ultrasound}

Ultrasound adalah gelombang suara yang memiliki frekuensi diatas $20 \mathrm{kHz}$ sampai beberapa GHz. Ultrasound tidak dapat didengar oleh manusia walaupun memiliki karakteristik fisik yang sama dengan suara yang

\footnotetext{
${ }^{1}$ Program Studi Teknik Elektro Universitas Kristen Maranatha
} 
dapat didengar manusia ( frekuensi $20 \mathrm{~Hz}$ sampai $20 \mathrm{kHz}$ ). Tetapi batas dari suara yang dapat didengar manusia berbeda dari satu manusia ke manusia yang lain.

\section{Ultrasonic Testing}

Ultrasonic Testing (UT) memiliki prinsip yang sama dengan SONAR (Sound Navigation And Ranging) bawah laut dalam hal mencari ikan dengan memancarkan suara ke dalam laut, suara tersebut akan terpantul apabila mengenai ikan. Pada Ultrasonic Testing (UT) terdapat banyak teknik, salah satunya ultrasound dipaparkan pada bagian dari material yang diinspeksi lalu apabila suara (Ultrasound) mengenai bagian dari material yang memiliki hambatan akustik yang berbeda (kepadatan dan kecepatan akustik) atau bisa disebut reflektor, beberapa dari suara (ultrasound) akan dipantulkan kembali kearah pengirim lalu dengan memperhatikan jumlah ultrasound yang terkirim dari transduser pemancar melintasi material sampai ke transduser penerima yang ditempatkan pada permukaan material yang berhadapan dengan transduser pemancar.

Dengan mengetahui jumlah ultrasound pada material yang tidak terdapat reflektor untuk menjadi nilai pembanding dengan material yang terdapat reflektor. Jumlah ultrasound yang diterima oleh transudser penerima setelah melintasi material yang tidak terdapat reflektor akan lebih banyak dibanding dengan jumlah ultrasound yang diterima oleh transduser penerima setelah melintasi material yang terdapat reflektor. Teknik ultrasonic testing ini dinamakan through transmission[3].

\section{Trough Transmission}

Through transmission inspections dilakukan menggunakan dua transduser, dengan kedua transdusernya ditempatkan terpisah berhadapan pada kedua sisi dari material yang diinspeksi, seperti pada Gambar 1 .

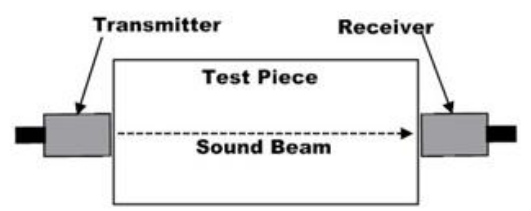

- Gambar 1. Letak Penyimpanan Transduser Pemancar dan Penerima pada Through Transmission Inspection

Transduser yang merupakan pemancar (transmitter) mengirim suara (ultrasound) melalui material yang diinspeksi lalu ultrasonik diterima oleh transduser penerima (receiver). Reflektor yang terdapat di antara kedua transduser (di dalam material yang diinspeksi) akan menyebabkan pengurangan dalam jumlah ultrasound yang mencapai transduser penerima (receiver), maka pada layar akan terlihat sinyal yang memiliki amplituda yang lebih rendah[3], ilustrasi dapat dilihat pada Gambar 2.

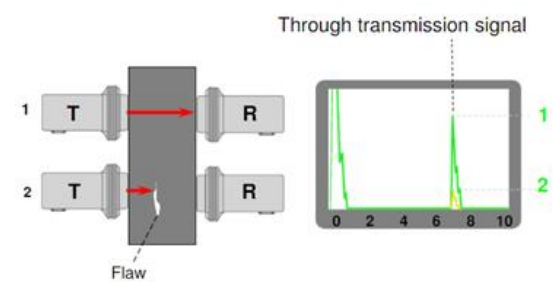

- Gambar 2. Prinsip dari Through Transmission Inspection[6]

\section{PERANCANGAN DAN REALISASI}

Alat uji tak rusak untuk peluruhan kayu bagian dalam memiliki transduser pemancar, trasnduser penerima yang dilengkapi dengan penguat (amplifier). ATmega328 digunakan sebagai mikrokontroler untuk mengatur pengiriman sinyal ultrasonik pada transduser pemancar, dan mengolah data yang didapat dari transduser penerima.

Transduser pemancar dilengkapi push-pull amplifier untuk memperkuat arus dan ditambahkan dioda untuk mengurangi distorsi dari sinyal ultrasonik 40kHz yang dibangkitkan oleh rangkaian NE555 mode Astable. Sinyal ultrasonik akan diterima oleh trasnduser penerima setelah melewati balok kayu yang diuji. Amplifier pada transduser penerima digunakan untuk memperkuat sinyal yang diterima (tegangan) sebesar empat kali untuk mendapatkan sekitar 5 volt pada masukan analog to digital converter ATmega328. 
Untuk menahan gangguan sinyal ultrasonik yang dibangkitkan oleh rangkaian NE555 terhadap ATmega328 digunakan rele. Keypad digunakan sebagai masukan untuk memilih menu pilihan yang ditampilkan pada LCD. LCD juga digunakan untuk menampilkan kondisi kayu hasil dari pengolahan data dari ATmega328. SD Card digunakan sebagai memori untuk menyimpan (dan mengambil) data informasi kondisi kayu sebagai referensi. LED akan menyala apabila kayu dinyatakan cacat oleh ATmega328. Diagram blok dan skematik alat [6] dapat dilihat pada Gambar 3 dan Gambar 4.

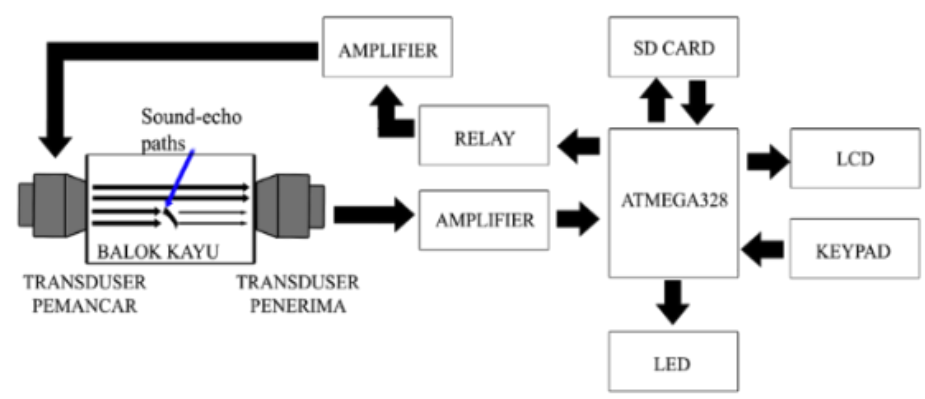

- Gambar 3. Diagram Blok Alat Uji Tak Rusak dengan Ultrasound

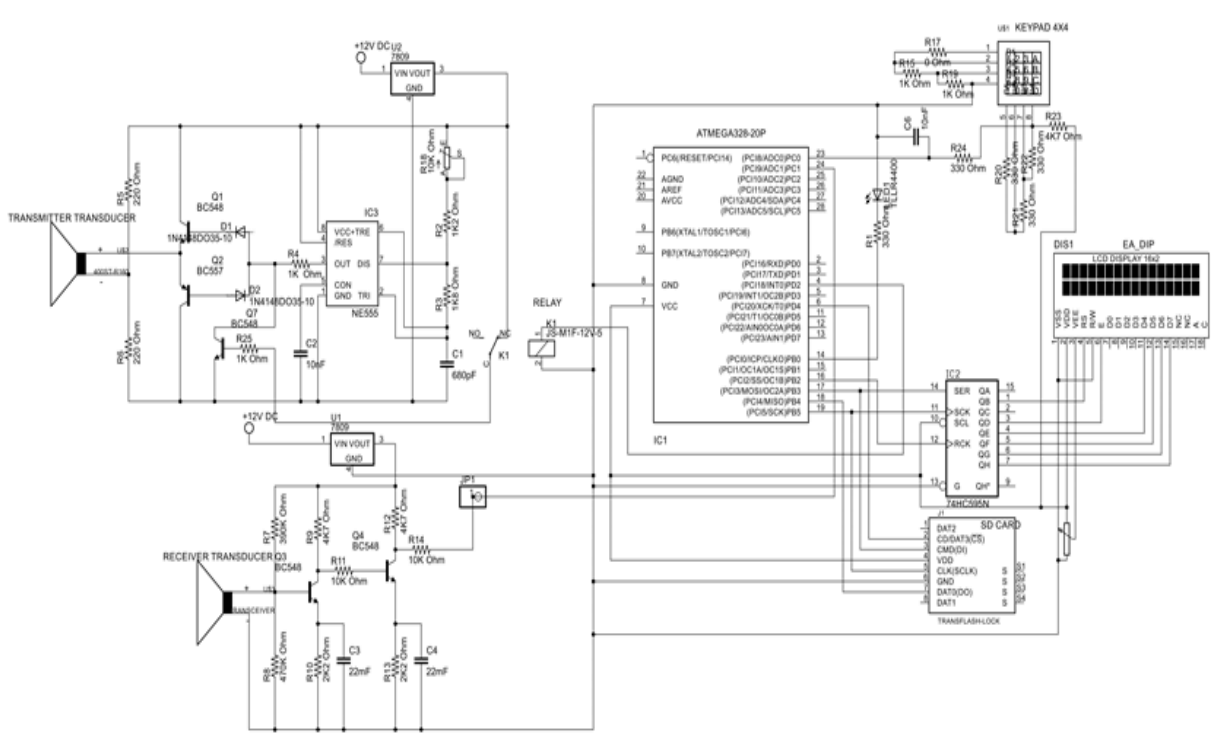

- Gambar 4. Skematik Rangkaian Alat Uji Tak Rusak dengan Ultrasound

Sinyal ultrasonik $40 \mathrm{kHz}$ tersebut dipancarkan oleh transduser pemancar, melewati balok kayu lalu diterima oleh transduser penerima. Kecepatan sinyal ultrasonik dalam material padat satu dimensi dapat dihitung dengan persamaan (1). Poisson's ratio untuk low-density wood dengan gelombang longitudinal adalah 0,40 $\pm 0,05$.

Kecepatan sinyal ultrasonik dalam kayu mahoni dengan massa jenis $(\rho) 0,675\left(10^{3} \mathrm{~kg} / \mathrm{m}^{3}\right)$ dan Modulus Young (E) 1.025.834.510,256( $\left.\mathrm{N} / \mathrm{m}^{2}\right)$ dengan Poisson's ratio (v) 0,40 adalah

$c=\sqrt{\frac{E(1-v)}{\rho(1+v)(1-2 v)}}$

$=\sqrt{\frac{1.025 .834 .510,256(1-0,4)\left(\mathrm{N} / \mathrm{m}^{2}\right)}{0,675(1+0,4)(1-2 \times 0,4)\left(10^{3} \mathrm{~kg} / \mathrm{m}^{3}\right)}}$

$=\sqrt{3.256 .617,493 \mathrm{~m}^{2} / \mathrm{s}^{2}}$

$=1804,610 \mathrm{~m} / \mathrm{s}$

Kecepatan sinyal ultrasonik dalam kayu albasia dengan massa jenis $(\rho) 0,47\left(10^{3} \mathrm{~kg} / \mathrm{m}^{3}\right)$ dan Modulus Young (E) 1.112.510.388,359( $\left.\mathrm{N} / \mathrm{m}^{2}\right)$ dengan Poisson's ratio (v) 0,40 adalah

$c=\sqrt{\frac{1.112 .510 .388,359(1-0,4)\left(\mathrm{N} / \mathrm{m}^{2}\right)}{0,470(1+0,4)(1-2 \times 0,4)\left(10^{3} \mathrm{~kg} / \mathrm{m}^{3}\right)}}$

$c=2252,162 \mathrm{~m} / \mathrm{s}$

Panjang gelombang dari sinyal ultrasonik dalam kayu mahoni dan kayu albasia dapat dihitung dengan persamaan (2).

Panjang gelombang dari sinyal ultrasonik dalam kayu mahoni adalah 
$\lambda=\frac{v}{f}$.

$\lambda=\frac{1804,610}{40000}$

$\lambda=4,5 \mathrm{~cm}$

Panjang gelombang dari sinyal ultrasonik dalam kayu albasia dengan adalah:

$\lambda=\frac{2252,162}{40000}$

$\lambda=5,6 \mathrm{~cm}$

Balok kayu yang dilintasi minimal panjangnya 5,6 cm agar satu gelombang sinyal ultrasonik penuh dalam kayu albasia dapat melintas. Maka balok kayu yang diuji dirancang sepanjang $8 \mathrm{~cm}$ untuk panjang lintasannya. Lebar dari balok kayu adalah $15 \mathrm{~cm}$ dikarenakan agar didapatkan 10 titik pengujian dengan lebar transduser kurang lebih $1,5 \mathrm{~cm}$. Pengujian dilakukan pada permukaan $4 \times 15 \mathrm{~cm}^{2}$ agar peluruhan kayu bagian dalam buatan dapat memiliki variasi.

\section{HASIL DAN PEMBAHASAN}

Gambar 5 memperlihatkan sinyal yang dihasilkan oleh pembangkitkan sinyal ultrasonik dengan frekuensi $40 \mathrm{kHz}$ menggunakan rangkaian NE555 mode Astable.

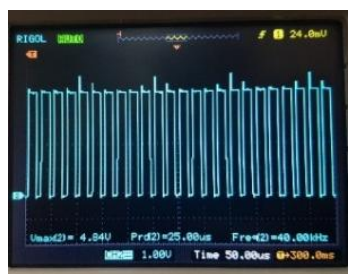

- Gambar 5. Sinyal Ultrasonik 40kHz yang Dibangkitkan NE555 Mode Astable

Sinyal tersebut kemudian melewati rangkaian push-pull amplifier yang dilengkapi dengan rangkaian dioda untuk mengurangi distorsi dan memperkuat arus sebelum dikirim ke transduser pengirim. Setelah diperkuat sinyal dikirimkan oleh transduser pengirim dengan jarak antar transduser pengirim dan penerima semaksimal mungkin lalu sinyal ultrasonik diterima oleh transduser penerima lalu diperkuat dua kali seperti pada Gambar 6.

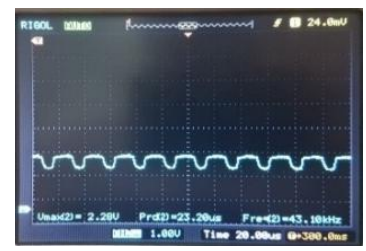

- Gambar 6. Sinyal Ultrasonik yang Diterima Transduser Penerima dan Telah Diperkuat Dua Kali

Lalu sinyal ultrasonik tersebut diperkuat dua kali kembali seperti pada Gambar 7. Maka total penguatan sinyal (tegangan) empat kali sesudah sinyal ultrasonik diterima oleh transduser penerima.

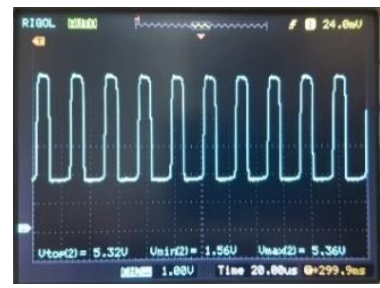

- Gambar 7. Sinyal Ultrasonik yang Diterima Transduser Penerima dan Telah Diperkuat Empat Kali

Sinyal ultrasonik dilewatkan pada kayu tanpa cacat dan didapat sinyal ultrasonik seperti pada Gambar 8. 


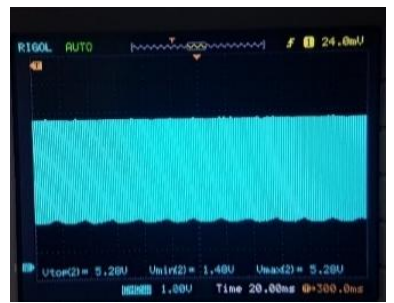

- Gambar 8. Sinyal Ultrasonik yang Diterima Transduser Penerima Setelah Melewati Kayu Tanpa Cacat Sesudah Diperkuat Empat Kali

Sinyal ultrasonik juga dilewatkan pada kayu dengan cacat, maka didapatkan sinyal ultrasonik seperti pada Gambar 9.

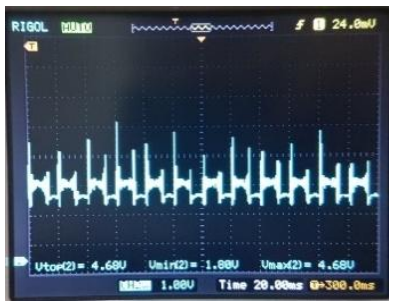

- Gambar 9. Sinyal Ultrasonik yang Diterima Transduser Penerima Setelah Melewati Kayu Dengan

Cacat Sesudah Diperkuat Empat Kali

Dapat diperhatikan pada sinyal ultrasonik yang dilewatkan pada kayu tanpa cacat dan kayu dengan cacat didapatkan bentuk sinyal dengan tegangan tertinggi (peak) yang berbeda. Tegangan ini yang akan diperhatikan dalam membedakan / mengklasifikasikan sinyal ultrasonik yang didapatkan. Sinyal ultrasonik akan diklasifikasikan menjadi sinyal ultrasonik yang menyatakan kondisi kayu pada titik uji tersebut mengalami peluruhan kayu bagian dalam (terdapat cacat / flaw) atau tidak. Tegangan yang akan diambil sebagai referensi kondisi tidak cacat adalah tegangan terendah pada saat pengukuran pada kayu kondisi bagus (tidak ada cacat).

Material yang diuji adalah empat balok Kayu Mahoni dan empat balok Kayu Albasia. Empat balok Kayu Mahoni tersebut adalah kayu referensi (M), kayu tanpa cacat (M0), kayu dengan cacat (M1), kayu dengan cacat diisi serpihan kayu kering (M2). Empat balok Kayu Albasia tersebut adalah kayu referensi (A), kayu tanpa cacat (A0), kayu dengan cacat (A1), kayu dengan cacat diisi serpihan kayu kering (A2). Realisasi dapat dilihat pada Gambar 10 dan Gambar 11
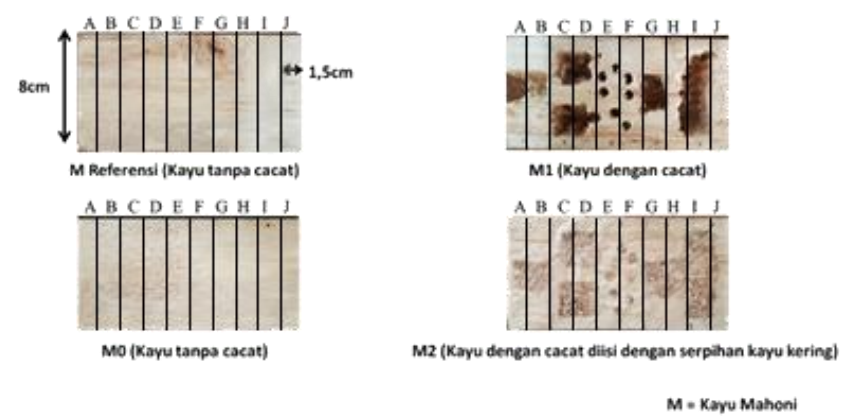

- Gambar 10. Realisasi Kayu Mahoni untuk Pengujian
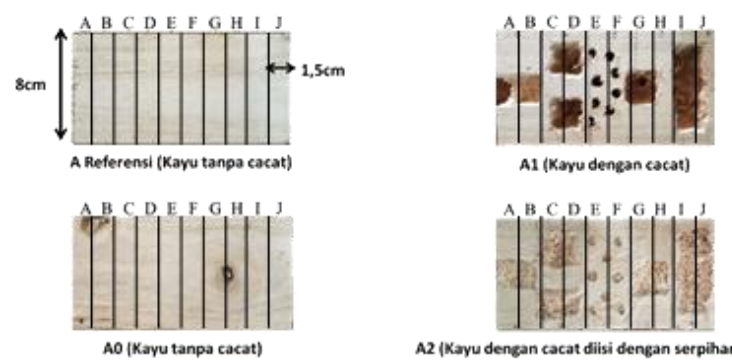

A2 (Kayu dengan cacat dilisi dengan seepihan kayu kering)

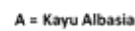

- Gambar 11. Realisasi Kayu Albasia untuk Pengujian 
Untuk mempermudah pengamatan balok kayu dikodekan $M$ untuk kayu Mahoni dan A untuk kayu Albasiah. Tiap balok kayu dibagi menjadi 10 daerah uji (dengan lebar masing-masing 1,5 Cm) dinotasikan daerah uji A sampai dengan $\mathrm{J}(\mathrm{A}, \mathrm{B}, \mathrm{C}, \mathrm{D}, . . \mathrm{J})$.

Dilakukan pengukuran nilai tegangan yang dihasilkan saat sinyal ultrasonik dikirimkan pada kayu Mahoni referensi (M) (sebanyak 5 kali pengujian pada tiap daerah uji) untuk mendapatkan nilai tegangan referensi dari jenis kayu mahoni yang diuji. Didapatkan data pada Tabel 1.

- Tabel 1. Data Kayu Mahoni Referensi (M)

\begin{tabular}{|l|r|r|r|r|r|r|r|r|r|r|}
\hline M Ref & \multicolumn{10}{|c|}{ Nilai Vref (Volt) } \\
\hline Pelatihan & \multicolumn{1}{|c|}{ A } & \multicolumn{1}{c|}{ B } & \multicolumn{1}{c|}{ C } & \multicolumn{1}{c|}{ D } & \multicolumn{1}{c|}{ E } & \multicolumn{1}{c|}{ F } & G & \multicolumn{1}{l|}{ H } & \multicolumn{1}{l|}{ I } & \multicolumn{1}{c|}{} \\
\hline 1. & 0,81 & 0,82 & 0,81 & 0,79 & 0,86 & 0,8 & 0,82 & 0,81 & 0,74 & 0,83 \\
\hline 2. & 0,79 & 0,79 & 0,79 & 0,8 & 0,81 & 0,78 & 0,81 & 0,76 & 0,73 & 0,78 \\
\hline 3. & 0,75 & 0,77 & 0,75 & 0,77 & 0,76 & 0,77 & 0,76 & 0,72 & 0,8 & 0,78 \\
\hline 4. & 0,81 & 0,82 & 0,82 & 0,81 & 0,81 & 0,81 & 0,79 & 0,83 & 0,83 & 0,82 \\
\hline 5. & 0,8 & 0,8 & 0,79 & 0,75 & 0,76 & 0,79 & 0,78 & 0,77 & 0,72 & 0,79 \\
\hline
\end{tabular}

Didapatkan nilai (tegangan) referensi minimum untuk kayu mahoni adalah 0,72 Volt.

Analisis data dihitung dengan persen keberhasilan alat benar menyatakan kayu tanpa / dengan cacat dengan persamaan (3) :

Keberhasilan $=\frac{\text { Data benar mendeteksi }}{\text { Data gagal mendeteksi }} \times 100 \%$

Selanjutnya dilakukan pengujian pada Kayu M0 yang merupakan kayu mahoni tanpa cacat, dan hasilnya ditunjukkan pada Tabel 2.

- Tabel 2. Data Kayu M0 (Kayu Mahoni Tanpa Cacat)

\begin{tabular}{|l|r|r|r|r|r|r|r|r|r|r|}
\hline M0 & \multicolumn{10}{|c|}{ Nilai Vdiff (Volt) } \\
\hline Pengujian & A & \multicolumn{1}{|c|}{ B } & \multicolumn{1}{c|}{ C } & \multicolumn{1}{c|}{ D } & \multicolumn{1}{c|}{ E } & \multicolumn{1}{c|}{ F } & \multicolumn{1}{c|}{ G } & \multicolumn{1}{c|}{ H } & I & J \\
\hline 1. & 0,8 & 0,78 & 0,75 & 0,77 & 0,77 & 0,79 & 0,8 & 0,84 & 0,8 & 0,79 \\
\hline 2. & 0,94 & 1,15 & 1 & 1 & 0,84 & 0,81 & 0,81 & 0,79 & 0,77 & 0,79 \\
\hline 3. & 0,8 & 0,79 & 0,79 & 0,79 & 0,98 & 0,82 & 0,84 & 0,83 & 0,79 & 1,01 \\
\hline 4. & 0,76 & 0,8 & 0,82 & 0,81 & 0,77 & 0,82 & 0,8 & 0,77 & 0,72 & 0,99 \\
\hline 5. & 0,76 & 0,75 & 0,77 & 0,77 & 0,75 & 0,93 & 0,75 & 0,96 & 0,73 & 0,7 \\
\hline
\end{tabular}

Didapatkan 1 nilai yang menyatakan kayu cacat (dibawah nilai refensi), dan 49 nilai menyatakan kayu tidak cacat (diatas atau sama dengan nilai referensi). Keberhasilan mendeteksi kayu tidak cacat dengan benar adalah $98 \%$.

Selanjutnya dilakukan pengujian pada Kayu M1 yang merupakan kayu mahoni dengan cacat, dan hasilnya ditunjukkan pada Tabel 3 .

- Tabel 3. Data Kayu M1 (Kayu Mahoni Dengan Cacat)

\begin{tabular}{|l|r|r|r|r|r|r|r|r|r|r|}
\hline M1 & \multicolumn{10}{|c|}{ Nilai Vdiff (Volt) } \\
\hline Pengujian & \multicolumn{1}{|c|}{ A } & \multicolumn{1}{c|}{ B } & \multicolumn{1}{c|}{ C } & \multicolumn{1}{c|}{ D } & \multicolumn{1}{c|}{ E } & \multicolumn{1}{c|}{ F } & \multicolumn{1}{c|}{ G } & H & \multicolumn{1}{c|}{ I } & \multicolumn{1}{c|}{ J } \\
\hline 1. & 0,46 & 0,56 & 0,66 & 0,63 & 0,13 & 0,29 & 0,43 & 0,33 & 0,16 & 0,27 \\
\hline 2. & 0,46 & 0,41 & 0,37 & 0,36 & 0,29 & 0,19 & 0,31 & 0,37 & 0,25 & 0,89 \\
\hline 3. & 0,38 & 0,13 & 0,18 & 0,17 & 0,72 & 0,34 & 0,69 & 0,66 & 0,71 & 0,99 \\
\hline 4. & 0,64 & 0,55 & 0,75 & 0,74 & 0,43 & 0,61 & 0,6 & 0,64 & 0,74 & 0,93 \\
\hline 5. & 0,62 & 0,3 & 0,83 & 0,6 & 0,76 & 0,75 & 0,31 & 0,38 & 0,47 & 0,37 \\
\hline
\end{tabular}

Didapatkan 10 nilai yang menyatakan kayu tidak cacat dan 40 data menyatakan bahwa kayu cacat. Keberhasilan benar mendeteksi kayu dengan cacat adalah $80 \%$.

Selanjutnya dilakukan pengujian pada Kayu M2 yang merupakan kayu mahoni dengan cacat diisi dengan serpihan kayu kering, dan hasilnya ditunjukkan data pada Tabel 4. 
- Tabel 4. Data Kayu M2 (Kayu Mahoni Dengan Cacat Diisi Serpihan Kayu Kering)

\begin{tabular}{|l|r|r|r|r|r|r|r|r|r|r|}
\hline M2 & \multicolumn{10}{|c|}{ Nilai Vdiff (Volt) } \\
\hline Pengujian & \multicolumn{1}{|c|}{ A } & \multicolumn{1}{c|}{ B } & \multicolumn{1}{c|}{ C } & \multicolumn{1}{c|}{ D } & \multicolumn{1}{c|}{ E } & \multicolumn{1}{c|}{ F } & \multicolumn{1}{c|}{ G } & \multicolumn{1}{c|}{ H } & \multicolumn{1}{c|}{ I } & \multicolumn{1}{c|}{ J } \\
\hline 1. & 0,56 & 0,87 & 0,78 & 0,84 & 0,92 & 0,6 & 0,6 & 0,62 & 0,94 & 0,35 \\
\hline 2. & 0,56 & 0,55 & 0,6 & 0,77 & 0,78 & 0,56 & 0,66 & 0,7 & 0,98 & 0,43 \\
\hline 3. & 0,2 & 0,27 & 0,22 & 0,23 & 0,31 & 0,31 & 0,37 & 0,34 & 0,91 & 0,61 \\
\hline 4. & 0,23 & 0,28 & 0,2 & 0,31 & 0,29 & 0,37 & 0,37 & 0,37 & 0,35 & 0,4 \\
\hline 5. & 0,34 & 0,75 & 0,72 & 0,83 & 0,83 & 0,43 & 0,75 & 0,62 & 0,93 & 0,52 \\
\hline
\end{tabular}

Didapatkan 14 nilai yang menyatakan tidak cacat, dan 36 data menyatakan bahwa kayu cacat. Keberhasilan benar mendeteksi kayu dengan cacat adalah $72 \%$.

Keberhasilan terbesar dalam mendeteksi kondisi kayu dengan benar adalah 98\% pada Kayu M0 dan terkecil adalah $72 \%$ pada kayu M2.

Selanjutnya dilakukan pengukuran nilai tegangan yang dihasilkan saat sinyal ultrasonik dikirimkan pada kayu Albasiah referensi (A) (sebanyak 5 kali pengujian pada tiap daerah uji) untuk mendapatkan nilai tegangan referensi dari jenis kayu Albasiah yang diuji. Hasilnya ditampilkan pada Tabel 5.

- Tabel 5. Data Kayu Albasia Referensi (A)

\begin{tabular}{|l|r|r|r|r|r|r|r|r|r|r|}
\hline A Ref & \multicolumn{10}{|c|}{ Nilai Vref (Volt) } \\
\hline Pelatihan & \multicolumn{1}{|c|}{ A } & \multicolumn{1}{|c|}{ B } & \multicolumn{1}{c|}{ C } & \multicolumn{1}{c|}{ D } & \multicolumn{1}{c|}{ E } & F & G & H & I & \multicolumn{1}{l|}{ J } \\
\hline 1. & 1,11 & 0,88 & 1,26 & 0,71 & 0,86 & 1,17 & 0,82 & 1,01 & 0,95 & 0,73 \\
\hline 2. & 1,26 & 1,1 & 1,29 & 1,14 & 0,74 & 1,33 & 0,89 & 1,23 & 0,82 & 0,92 \\
\hline 3. & 1,08 & 0,9 & 0,97 & 1,14 & 0,71 & 1,25 & 0,79 & 0,94 & 0,8 & 1,32 \\
\hline 4. & 1,31 & 1,04 & 1,1 & 0,97 & 0,71 & 1,28 & 0,82 & 0,71 & 0,74 & 0,82 \\
\hline 5. & 1,11 & 0,74 & 1,09 & 1,24 & 0,76 & 1,08 & 1,23 & 1,33 & 1,13 & 1,06 \\
\hline
\end{tabular}

Didapatkan nilai (tegangan) referensi minimum untuk kayu Albasiah adalah 0,71 Volt.

Selanjutnya dilakukan pengujian pada kayu A0 yang merupakan kayu albasiah tanpa cacat dan hasilnya ditunjukkan pada Tabel 6.

- Tabel 6. Data Kayu A0 (Kayu Albasia Tanpa Cacat)

\begin{tabular}{|l|r|r|r|r|r|r|r|r|r|r|}
\hline A0 & \multicolumn{10}{|c|}{ Nilai Vdiff (Volt) } \\
\hline Pengujian & \multicolumn{1}{|c|}{ A } & \multicolumn{1}{|c|}{ B } & \multicolumn{1}{c|}{ C } & \multicolumn{1}{c|}{ D } & \multicolumn{1}{c|}{ E } & \multicolumn{1}{c|}{ F } & \multicolumn{1}{c|}{ G } & H & I & \multicolumn{1}{c|}{ J } \\
\hline 1. & 0,97 & 0,83 & 0,98 & 0,85 & 0,85 & 0,98 & 0,89 & 1,11 & 0,97 & 1,22 \\
\hline 2. & 0,84 & 0,76 & 0,81 & 0,69 & 0,76 & 1,11 & 1,01 & 0,98 & 0,76 & 1,1 \\
\hline 3. & 1,02 & 0,7 & 0,83 & 0,76 & 1,12 & 0,81 & 0,82 & 1,01 & 0,86 & 0,72 \\
\hline 4. & 0,96 & 0,98 & 0,96 & 0,93 & 0,96 & 0,96 & 0,84 & 0,93 & 0,83 & 0,88 \\
\hline 5. & 0,88 & 0,71 & 0,85 & 0,76 & 0,7 & 0,76 & 0,75 & 0,72 & 0,88 & 1,13 \\
\hline
\end{tabular}

Didapatkan 3 nilai menyatakan kayu cacat (dibawah nilai refensi) dan 47 nilai menyatakan kayu tidak cacat (diatas atau sama dengan nilai referensi). Keberhasilan mendeteksi kayu tanpa cacat dengan benar adalah 94\%.

Selanjutnya dilakukan pengujian pada Kayu A1 yang merupakan kayu albasia dengan cacat, hasil pengujian ditunjukkan pada Tabel 7.

- Tabel 7. Data Kayu A1 (Kayu Albasia Dengan Cacat)

\begin{tabular}{|l|r|r|r|r|r|r|r|r|r|r|}
\hline A1 & \multicolumn{10}{|c|}{ Nilai Vdiff (Volt) } \\
\hline Pengujian & \multicolumn{1}{|c|}{ A } & \multicolumn{1}{c|}{ B } & \multicolumn{1}{c|}{ C } & \multicolumn{1}{c|}{ D } & \multicolumn{1}{c|}{ E } & \multicolumn{1}{c|}{ F } & \multicolumn{1}{c|}{ G } & \multicolumn{1}{c|}{ H } & \multicolumn{1}{c|}{ I } & J \\
\hline 1. & 0,44 & 0,5 & 0,64 & 0,57 & 0,61 & 0,67 & 0,65 & 0,68 & 0,76 & 0,78 \\
\hline 2. & 0,3 & 0,32 & 0,29 & 0,44 & 0,5 & 0,6 & 0,56 & 0,59 & 0,62 & 0,66 \\
\hline 3. & 0,3 & 0,31 & 0,31 & 0,32 & 0,36 & 0,42 & 0,48 & 0,57 & 0,46 & 0,52 \\
\hline 4. & 0,29 & 0,27 & 0,28 & 0,54 & 0,73 & 0,48 & 0,76 & 0,47 & 0,37 & 0,45 \\
\hline 5. & 0,22 & 0,27 & 0,28 & 0,3 & 0,33 & 0,6 & 0,73 & 0,47 & 0,75 & 0,93 \\
\hline
\end{tabular}

Didapatkan 7 nilai menyatakan kayu tidak cacat dan 43 nilai menyatakan bahwa kayu cacat. Keberhasilan mendeteksi kayu dengan cacat dengan benar adalah $86 \%$.

Selanjutnya dilakukan pengujian pada Kayu A2 yang merupakan kayu albasia dengan cacat diisi dengan serpihan kayu kering,hasil pengujian ditunjukan pada Tabel 8. 
- Tabel 8. Data Kayu A2 (Kayu Albasia Dengan Cacat Diisi Serpihan Kayu Kering)

\begin{tabular}{|c|c|c|c|c|c|c|c|c|c|c|}
\hline A2 & \multicolumn{10}{|c|}{ Nilai Vdiff (Volt) } \\
\hline Pengujian & A & B & C & D & $\mathrm{E}$ & $\mathrm{F}$ & G & $\mathrm{H}$ & 1 & J \\
\hline 1. & 0,97 & 0,99 & 0,57 & 0,59 & 0,97 & 0,72 & 0,66 & 0,65 & 0,62 & 0,56 \\
\hline 2. & 0,94 & 0,92 & 0,48 & 0,55 & 0,85 & 0,78 & 0,84 & 0,58 & 0,43 & 0,53 \\
\hline 3. & 0,92 & 0,39 & 0,34 & 0,47 & 0,69 & 0,73 & 0,61 & 0,24 & 0,36 & 0,24 \\
\hline 4. & 0,32 & 0,35 & 0,33 & 0,62 & 0,42 & 0,42 & 0,34 & 0,37 & 0,4 & 0,4 \\
\hline 5. & 1,07 & 0,95 & 0,64 & 0,5 & 0,53 & 0,39 & 0,6 & 0,32 & 0,27 & 0,47 \\
\hline
\end{tabular}

Didapatkan 13 nilai menyatakan kayu tidak cacat dan 37 nilai menyatakan bahwa kayu cacat. Keberhasilan mendeteksi kayu dengan cacat dengan benar adalah $74 \%$.

Keberhasilan terbesar dalam mendeteksi kondisi kayu Albasiah dengan benar adalah 94\% pada Kayu A0 dan terkecil adalah $74 \%$ pada kayu A2.

\section{KESIMPULAN}

Alat yang telah dirancang dan direalisasikan dinyatakan berhasil dalam mendeteksi dan mengklasifikasi peluruhan kayu bagian dalam pada Kayu Mahoni dan Kayu Albasia yang diuji.

Persentase keberhasilan mendeteksi terjadi peluruhan/tidak kayu bagian dalam per titik uji dengan benar, tertinggi didapat pada kayu tanpa cacat (Kayu Mahoni 98\% dan Kayu Albasia 94\%).

Persentase keberhasilan mendeteksi terjadi peluruhan/tidak kayu bagian dalam per titik uji dengan benar, terendah didapat pada kayu dengan cacat diisi serpihan kayu kering (Kayu Mahoni 72\% dan Kayu Albasia 74\%).

Alat ini belum dirancang untuk mengetahui jarak antara transduser dengan perluruhan kayu bagian dalamnya.

\section{UCAPAN TERIMA KASIH}

Penulis ingin berterimakasih kepada seluruh pihak yang mendukung atas terselesaikannya penelitian mengenai alat uji tak rusak dengan ultrasound untuk peluruhan kayu bagian dalam. Penulis juga ingin berterimakasih kepada Program Studi Teknik Elektro Universitas Kristen Maranatha, yang sudah meminjamkan Laboratorium Komputer, Laboratorium Sistem Kontrol, Laboratorium Robotika dan Laboratorium Elektronika sebagai tempat untuk mendukung penelitian ini.

\section{DAFTAR PUSTAKA}

[1] Schubert, Sandy, Acousto-Ultrasound Assessment of Inner Wood Decay in Standing Trees. Diss. ETH Nr. 17126, ETH Zürich, 2007.

[2] Oliveira, Fabiana Goia R. dan Campos, Janaína Anadia O. dan Sales, Almir, Ultrasonic Measurements In Brazilian Hardwood. Materials Research, Vol. 5, No. 1, 51-55, São Carlos - SP, Brazil, 2002.

[3] The American Society For Nondestructive Testing. "Introduction to Nondestructive Testing", 2017. Internet : https://asnt.org/MinorSiteSections/AboutASNT/Intro-to-NDT.aspx\#UT [Juni 2018]

[4] Cartz, Louis, Nondestructive Testing. A S M International. ISBN 978-0-87170-517-4, 1995.

[5] K.H.J. Buschow et al, Encyclopedia of Materials Elsevier. ISBN 0-08-043152-6 p. 5990, 2001.

[6] Hianjaya Raymond. "Perancangan dan Realisasi Alat Uji Tak Rusak Portabel untuk Peluruhan Kayu Bagian Dalam Menggunakan Sensor Acousto-Ultrasound dan Atmega328”. Bandung, Indonesia, 2018. 